\title{
SHAKESPEARE E A PRÁTICA DA COLABORAÇÃO: O CASO DE SIR THOMAS MORE E SUA TRADUÇÃO ${ }^{1}$
}

\author{
Régis Augustus Bars Closel
}

I come to accept Shakespeare, not to praise

him.

E. K. CHAMBERS

Duas noções parecem ser fundamentais no entendimento atual sobre Shakespeare: a ideia de autoria e o cânone. No entanto, estas vêm sendo distorcidas devido à potencialidade de alcance — seja no teatro, em livros ou filmes — tanto de sua obra como no uso do nome que iluminaria a produção seiscentista inglesa quase isoladamente, se não fosse a expansão do gênero utopia e seus desdobramentos em distopias e ficções científicas através da obra-prima de Thomas More. Se essa situação for pensada como um fenômeno em suas duas faces, as consequências históricas são facilmente observáveis. Shakespeare possui um texto de status sacralizado. Esta afirmação, embora não soe estranha ${ }^{2}$ (quando aplicada a Shakespeare), merece cuidado, pois estipula tanto uma aparente "estabilidade de texto"3 como uma relação entre homem e obra que, na melhor visão, são compatíveis apenas com uma leitura contemporânea da realidade do pensamento sobre literatura. ${ }^{4}$ Porém, essas duas

\footnotetext{
${ }^{1}$ Trabalho apresentado na IV Jornada de Estudos Shakespearianos, realizada de 24 a 26 de outubro de 2012 na Universidade de São Paulo (USP).

2 José Roberto O'Shea, em sua tradução de The Winter's Tale ( $O$ Conto de Inverno), no ensaio que precede a peça, intitulado "Dessacralizando o 'Verbo' Shakespeariano: Tradução Linguística e Cultural" (2007, p. 29-36), debate de maneira clara este aspecto do texto de Shakespeare.

${ }^{3}$ Os termos, estabilidade e instabilidade textuais, são utilizados, ao longo deste artigo, referenciando-se à obra Shakespeare \& Text, de John Jowett (2012), no qual o texto shakespeariano é visto como algo repleto de variações, pertencente ao universo da cultura da performance. Esta instabilidade reflete-se em caráter textual - como modernizações de grafia, pontuação e edição - e também no caráter semântico e crítico-interpretativo dessas mesmas palavras, versos, rubricas e suas variações entre Quarto(s) e Fólio.

${ }^{4}$ Sobre este assunto, James Shapiro, lucidamente, nos recorda que, neste aspecto, Shakespeare não é nosso contemporâneo, pois "while Shakespeare was a product of an early modern world, the controversy over the authorship of his works is the creation of a modern one. As a result there's a danger of reading the past through contemporary eyes - from what Shakespeare's contested will really meant to how writers back then might have drawn upon personal experiences in their works" (2010, p. 10, meus destaques). Tradução de Liliana Negrello e Christian Schwartz: "Shakespeare é produto de um mundo pré-moderno, ao passo que a controvérsia da autoria é uma criação da modernidade. Ou seja, é um perigo observar o passado com olhos contemporâneos" (Shapiro, 2012, p. 11-12, meus destaques). Apesar de se tratar de um livro que debate a questão autoral da obra de Shakespeare como um bloco, vale destacar que ele faz sua apologia ao Shakespeare de Stratford-Upon-Avon, recorrendo, em diversos momentos, a autoria colaborativa (2010, p. 64; 283; 290; entre outros). No livro lançado recentemente — abril de 2013
} 
CLOSEL - Shakespeare e a prática da colaboração...

relações, quando pensadas para a obra de Shakespeare, estão extremamente deslocadas da realidade - de produção, conservação e publicação - do período que produziu estes textos e da forma como eles, ao longo de diversos séculos, foram transmitidos e obtiveram a forma e a quantidade que têm hoje em suas mais diversas mídias.

O simples exercício de comparação de uma versão de alguma peça em edições modernas com praticamente qualquer versão impressa - em Quarto ou em Fólio durante o período elisabetano e jacobino já apontaria para a estratégia textual predominante das edições atuais: a conflação. Neste método editorial, em geral, as diversas versões impressas ${ }^{5}$ existentes são reunidas e mescladas, determinando uma versão - cujas palavras também passam por um processo de modernização —, que não tem nenhum precedente histórico. Isso se deve a uma série de fatores, entre eles à opção geral pelo texto do Primeiro Fólio e o julgamento estético - historicamente localizado - de uma ou outra versão no processo de estabelecimento do texto. Segundo observa José Roberto O'Shea (2010), na introdução de sua tradução inédita do primeiro Quarto de Hamlet (Q1, 1603) para o português, as edições conflacionadas correspondem a "um texto que Shakespeare não escreveu e jamais viu encenado" (p. 11).

A existência de diferentes versões em alguns casos, como as peças históricas, que possuem muitas versões em formato Quarto para a mesma peça ${ }^{6}$, é relevante para se pensar o modo de transmissão do texto dramático. Ao mesmo tempo em que esse conjunto de impressões conserva a peça, ele também conta uma história que não é o enredo em si, mas como ele foi adaptado, modificado, reduzido e ampliado em seu próprio tempo, explicitando, portanto, o caráter instável do texto (Cf. Jowett, 2012) durante os anos em que eram ainda peças extremamente recentes ao palco e ao público. É neste ambiente dinâmico e marcado pela necessidade latente de adaptação, no qual a escrita para o teatro está muito distante das noções modernas de autoria e cânone, que as peças imortais de Shakespeare foram concebidas.

\footnotetext{
— sobre a questão autoral, Shakespeare Beyond Doubt: Evidence, Argument, Controversy, John Jowett aborda essa temática via colaboração (2013, p. 88-99).

${ }^{5}$ Cerca de metade das peças que compõem o Primeiro Fólio (1623), possuíram alguma versão anterior, geralmente designada pelo termo de Quarto - referente à quantidade de dobras que o papel recebia, neste caso, duas vezes - antes de serem reunidas em um único volume. Entre os diversos Quartos e Fólios existem diferenças, em alguns casos de palavras, em outros de versos ou nome de personagens ou sequências maiores. Sobre este assunto, ver Jowett (2012).

${ }^{6}$ Ricardo III, para efeito de exemplo, possui oito versões Quarto (Siemon, 2009, p. 417-60) e fora reproduzida também nos quatro Fólios publicados no século XVII.
} 
CLOSEL - Shakespeare e a prática da colaboração...

A quantidade de peças produzidas era imensa. Segundo Stanley Wells, cada companhia, em média, necessitava de um repertório de cerca de 40 peças, considerando que as remontagens eram mínimas. Geralmente o trabalho de se escrever não estava vinculado a uma relação entre um dramaturgo e uma companhia. Este seria o único aspecto que Shakespeare pode ser visto quase como uma exceção por ter escrito praticamente sempre para o mesmo grupo durante seu período produtivo. Por outro lado, o dramaturgo Thomas Heywood, autor de muitas peças conhecidas, alegava ter uma mão ou pelo menos um dedo em cerca de 220 peças (Bentley, 1971, p. 27; Wells, 2006, p. 22-23). A prática de uma peça não ser escrita sozinha era tão comum que se estima, segundo Eric Rasmussen, que pelo menos metade das peças escritas para o teatro público eram de autoria composta (2001, p. 80-82), enquanto para outros essa estimativa ainda é bem modesta (McMullan, 2000, p. 183-184). No caso das peças anotadas no Diário de Henslowe ${ }^{7}$, das 282 entradas, cerca de dois terços eram coautoradas (Bentley, 1971, p. 199).

Para suprir essa demanda de peças teatrais — das quais, por motivos variados, a maioria não iria alcançar a impressão (Cf. Bentley, 1971, p. 264-292) —, muitas delas foram escritas de maneira colaborativa. Segundo Stanley Wells, em Shakespeare \& Co., neste ambiente cultural,

[c]ollaboration may have evolved as a means of throwing plays together in a hurry, but at its best could act as an imaginative stimulus, a pooling of diverse talents conductive to a wider range of dramatic style than individual authors might have achieved on their own. $^{8}$ (Wells, 2006, p. 27)

Entretanto, devido à predominância do fenômeno descrito acima, a relação entre o autor solitário e o conjunto inviolável de sua obra — o cânone —, a compreensão da prática da autoria colaborativa das peças do dramaturgo mais encenado no mundo enfrentou muita relutância em sua história, pois inseria novos personagens dividindo os créditos

\footnotetext{
${ }^{7}$ Diário de Henslowe: Documento no qual o gerente da companhia de teatro "The Admiral's Men”, Philip Henslowe, fazia suas anotações, entre 1590 e 1604, registrando itens como o pagamento aos dramaturgos por peças, gastos com figurino, atores, entre outros. O Diário é a base para entender o dia-a-dia de uma companhia teatral elisabetana (Cf. Wells, 2006, p. 19-20) e é a maior prova da predominância do modo colaborativo de trabalho na redação de peças (Melchiori, 2012 [1990], p. 13).

${ }^{8}$ Tradução: Colaboração pode ter surgido como um meio de se produzir peças com mais rapidez, mas, em sua melhor aplicação, poderia agir como um estímulo imaginativo, uma reunião de talentos diversos para alcançar uma gama mais ampla de estilos dramáticos do que os autores individuais poderiam alcançar sozinhos.
} 
CLOSEL - Shakespeare e a prática da colaboração...

com o nome usualmente visto como aquele que produziu a peça - geralmente figuras pouco ou jamais conhecidas por alguns leitores, algo que, na verdade, é uma das consequências da visão de autoria solitária.

Por algum tempo os estudos de atribuição, que são o ramo de pesquisa textual que verifica de forma pormenorizada trechos, cenas e atos das peças buscando identificar padrões e anomalias (como a presença de outro dramaturgo), fora chamado de "desintegração", como na memorável fala de E. K. Chambers, em 1924, contra esse tipo de análise. Décadas depois, os estudos de atribuição recebem significativos avanços que, em alguns casos, confirmaram e deram sentido e relevância às intuições e registros sobre autorias colaborativas — através do uso de computadores e técnicas mais complexas e abrangentes. Entre os métodos, de maneira muito breve, podem-se enumerar algumas práticas utilizadas, ao longo dos anos, pelos estudos de atribuição. Segundo Gary Taylor, elas se baseiam na repetibilidade de certos aspectos na obra do autor, entre eles: a evidência biográfica, paleográfica ou cronológica; procedência teatral; vocabulário; uso de imprecações e exclamações; frequência de imaginário; conjunto imagético e suas associações; paralelos verbais e estruturais; evidências métricas ou linguísticas; as maneiras de lidar com as rubricas; estilometria; uso de palavras específico-funcionais (1997, p. 76-81). Esses aspectos são considerados evidências internas, pois ligam obras e autores a partir do seu próprio texto. Casos em que existem documentos que atestam as atribuições que não sejam o texto são chamados de evidências externas.

Oito décadas após Chambers, Vickers propõe que o estudo que dá a cada participante a sua respectiva parte, fazendo justiça com cada pessoa envolvida, deveria se chamar "restituição" e não desintegração (2004, p. 137-138). Esta postura se diferencia, em certa medida, daquela - específica para o período em que Chambers escrevera o referido texto, mas em alguns pontos ainda reproduzida — em que trechos ou peças que não agradavam eram atribuídos a outros autores — os "intrusos" (1924, p. 7) —, configurando a desintegração contra a qual ele se posicionava.

Portanto, a partir da expansão e do desenvolvimento dos estudos de atribuição, da intrusão para justificar momentos de menor expressividade, a colaboração passa a ser entendida como um fenômeno próprio das condições de produção da época que não tem relação com o julgamento estético, e sim com evidências internas e/ou externas. 
Afora as resistências anunciadas ou veladas — quando esta questão é ignorada —, a autoria colaborativa de peças de Shakespeare é defendida por muitas autoridades nos estudos shakespearianos, contando principalmente com a presença dos responsáveis pela organização de edições de Obras Completas da Oxford Shakespeare (1986) e seu respectivo Textual Companion (1987) ${ }^{9}$ — como é o caso de Stanley Wells, Gary Taylor, John Jowett e William Montgomery —, da Royal Shakespeare Company (2007) — Jonathan Bate e Eric Rasmussen - e também por parte dos editores individuais de cada volume da Arden Shakespeare Third Series para as peças que tiveram a colaboração discutida. Além das peças, livros novos sobre o modo de produção dos textos, sobre a transição da performance para o papel e os estudos de atribuição têm dado atenção ao tema.

O processo de colaboração que envolve as peças de Shakespeare pode ser dividido em quatro grupos, observando-se alguns padrões de variação: as peças que Shakespeare teria escrito em conjunto com um segundo dramaturgo; as peças que sofreram alterações postumamente, cujas mudanças foram transmitidas em outros textos; um terceiro grupo compreende os casos em que ele colaborou com alguma adição em uma peça já existente por parte de um ou mais dramaturgos; o quarto grupo, por fim, envolve o caso em que a peça possui algum tipo de relação com Shakespeare, mas os participantes e suas partes ainda não estão claramente definidos.

Os exemplos do primeiro grupo são os mais conhecidos e amplamente reconhecidos. Segundo Wells e Jowett, a quantidade de peças de Shakespeare que possuem uma segunda mão consiste em um grupo razoável, Titus Andronicus ${ }^{10}(1592)^{11}$ com George Peele, King Henry VI Part $I^{12}$ (1592) com Thomas Nashe, King Henry

\footnotetext{
${ }^{9}$ Neste texto foi utilizada a versão de 1997, com correções.

${ }^{10}$ Jonathan Bate, editor de Titus Andronicus pela Arden Shakespeare Third Series, recorda que a peça é um caso diferenciado, pois no início do século XX havia um clima de desconfiança quanto a sua autoria. Alguns críticos, possivelmente chocados com uma trama tão violenta, questionavam se Shakespeare a teria escrito, apesar das evidências externas o referenciando a ela, como a feita por Francis Meres em 1598. Por fim, a questão se confinou na discussão da autoria apenas da primeira cena, atribuída a George Peele (Cf. Bate, 2002, p. 79-80), ou como propõe Taylor, um possível imitador do estilo de Peele, que se diferencia do resto da peça, caracterizando a colaboração (Taylor, 1997, p. 115).

${ }^{11}$ A referência adotada para as datas, ao longo deste artigo, é a cronologia do Oxford Textual Companion (Wells \& Taylor, 1997) para as obras de Shakespeare e também para Fletcher.

${ }^{12}$ Edward Burns, editor de King Henry VI Part I pela Arden Shakespeare Third Series, ao comentar sobre a colaboração desta peça, em sua introdução, reforça que a necessidade de se tratar de King Henry VI Part I, por Shakespeare é meramente uma convenção (Burns, 2000, 84). Taylor sugere que haveria a presença de pelo menos mais dois dramaturgos nesta peça, sendo um deles possivelmente, o poeta Thomas Nashe, em boa parte do Ato I (Taylor, 1997, p. 112).
} 
VIII $^{13}$ (1613), Two Noble Kinsmen ${ }^{14}(1613-4)$ e a perdida Cardenio ${ }^{15}$ (1612-3) com John

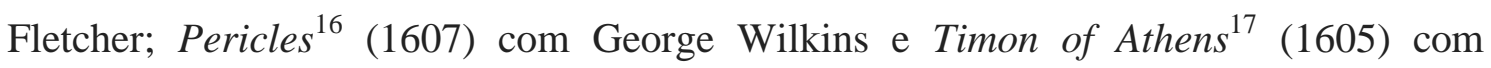
Thomas Middleton (Wells, 2006, p. 26; Jowett, 2012, p. 17). O fato da relativa impopularidade dessas em relação às outras não indica necessariamente uma coincidência $^{18}$, mas algo que também reflete um dos desafios dos estudos de atribuição, pois "the more important the play or the proposed author, the greater the degree of

\footnotetext{
${ }^{13}$ Gordon McMullan, editor de King Henry VIII pela Arden Shakespeare Third Series, ao longo de todo o texto da longa introdução, procura reforçar a importância do tópico da colaboração antes de dedicar-lhe uma seção que a encerra. O editor é muito claro em admitir que "I do not think Shakespeare wrote Henry VIII all by himself" (Tradução: Eu não acho que Shakespeare escreveu Henry VIII sozinho); reforçando, ao longo de sua explicação sobre os motivos, da importância fundamental da colaboração para se compreender o drama desse período, além de apontá-la como o fator que, ao longo do século XX, fez com que a peça fosse negligenciada pelos críticos. Aqueles que a favorecem a atribuem integralmente a Shakespeare, mas, quando não é este o caso, culpam Fletcher (McMullan, 2000, p. 180-199, citação na p. 180).
}

${ }^{14}$ Lois Potter, editora de Two Noble Kinsmen pela Arden Shakespeare Third Series, se dirige primeiramente a questão da colaboração, ressaltando as condições culturais em que a peça fora escrita, procurando dar clareza ao processo de composição da peça (Porter, 2002, p. 1-34). A peça foi publicada apenas após o Segundo Fólio (1632) em 1634, (Proudfoot, 2001, p. 68). Chambers reproduz a entrada de seu registro, feito em 8 de abril de 1634, "Master John Waterson Entred for his copy under the hands of Sir Henry Herbert and master Aspley warden a Tragi Comedy called the two noble kinsmen by John Fletcher and William Shakespeare”, no Quarto de 1634, também há menção aos dois nomes (Chambers, 1930, vol. 1, p. 528). Desde 1966 esta peça integra diversas coleções de obras completas (Melchiori, 2012 [1990], p. 2). Na edição da New Cambridge Shakespeare, preparada por Robert K. Turner e Patricia Tatspaugh, o leitor é informado, a cada cena, a qual dos dramaturgos ela é atribuída (Cf. Shakespeare \& Fletcher, 2012).

${ }^{15}$ Cardenio ou o título do século XVIII, Double Falsehood, é uma peça que se baseia em episódios de Dom Quixote. No caso do segundo título, mencionado novamente mais abaixo, trata-se de uma versão da peça perdida a que Lewis Theobald possivelmente teve acesso e realizou adaptações em 1727. Apesar das controvérsias sobre a autenticidade de suas origens, é o que existe de mais próximo a Cardenio (Cf. Hammond, 2010). Brean Hammond, editor deste texto pela Arden Shakespeare Third Series, também reconhece o seu caráter colaborativo e o papel fundamental desta prática (p. 91). Segundo ele, Double Falsehood pode ser definido como "a palimpsest that contains elements dating back to $c$. 1611-12, elements dating to the mid-1660s, and elements first introduced in the mid-to-late 1720s" (p. 55). (Tradução: um palimpsesto que contém elementos que remontam para 1611-12, elementos apontando para o meio da década de 1660, e elementos que somente aparecem no fim da década de 1720).

${ }^{16}$ Suzanne Gossett, editora de Pericles pela Arden Shakespeare Third Series, defende a atribuição dos dois primeiros atos a George Wilkins (2004, p. xvii-xviii; 161-163); a editora dedica boa parte de suas reflexões, ao longo da introdução, a este assunto.

${ }^{17}$ Anthony Dawson e Gretchen Minton, editores de Timon of Athens pela Arden Shakespeare Third Series, abordam a questão da colaboração logo na primeira página da introdução, indicando que a presente edição é uma edição colaborativa, reforçando que ambos os autores possuem suas características peculiares (2008, p. 1-2). A edição da Oxford, preparada por John Jowett, é outra que também defende a autoria de Thomas Middleton, detalhadamente em sua introdução (Shakespeare \& Middleton, 2004).

${ }^{18}$ No caso de traduções para o português esta situação também se constata, para Titus Andronicus e Pericles há quatro traduções, três para Timon of Athens, King Henry VI Part I e King Henry VIII e nenhuma para Two Noble Kinsmen, totalizando dezessete traduções para as seis peças colaborativas. Para esta contagem foi utilizada a base "Escolha o seu Shakespeare", organizada pela Profa. Dra. Marcia A. P. Martins (PUC-Rio). Vale destacar que, na tradução de Pericles, José Roberto O'Shea apresenta, antes de sua tradução da peça, um ensaio sobre a participação de Wilkins (Cf. O'Shea, 2012, p. 33-37). 
CLOSEL - Shakespeare e a prática da colaboração...

scepticism a case for authorship will attract"19 (Jackson, 1979, p. 161, apud Vickers, 2004, p. 46).

A relação de Shakespeare com John Fletcher não se limita às peças colaborativas, mas também a um diálogo entre peças de um com o outro. Segundo Clare McManus e Lucy Munro, Fletcher, como um sucessor do lugar de Shakespeare no King's Men, tomou alguns dos mesmos temas, ora convergindo ou divergindo do tratamento dado pelo seu predecessor. O caso mais notável e conhecido talvez seja a sequência para a The Taming of the Shrew (1590-1), intitulada de The Tamer Tamed or the Woman's Prize (1611). Escrevendo ao lado de Philip Massinger, Fletcher responde a The Tempest (1611) com a peça Sea Voyage (1647), e, com Francis Beaumont, apropria-se de Hamlet (1601) em Philaster (1609), peça cujo estilo será reaproveitado em Cymbeline (1610) (McManus et Munro, 2011, p. 253-254; Gossett, 2009; Jowett, 2013, p. 96). ${ }^{20}$

Além dessas, a relação de Thomas Middleton com Shakespeare toca em peças que estão muito mais próximas dos leitores além das peças citadas acima. Segundo os críticos textuais, ele teria revisado cenas e expandido uma das tragédias mais importantes, Macbeth (1606), e alterado vários pontos, inclusive a localização do cenário onde se passa a ação de Measure for Measure (1603) (Taylor \& Jowett, 1993; Wells, 2006, p. 167-193). Essas mudanças teriam ocorrido após 1606 - um período em que novas leis de censura exigem a remoção de profanações dos palcos - em encenações feitas após a morte de Shakespeare (Jowett, 2012, p. 42-45; Wells, 2006, p. 26-27; 164; 189-191). Gary Taylor também defende a possibilidade de que Middleton estivesse trabalhando com Shakespeare em colaboração em Macbeth, devido à proximidade com a data de Timon of Athens (1997, p. 129). Estas duas peças, Measure for Measure e Macbeth, formam o segundo grupo de peças colaborativas. Vale destacar que as peças citadas até então são obras que, de forma consciente ou não por parte de Shakespeare, receberam colaboração ou intervenção de outros dramaturgos que permaneceram nos textos atuais. Tais participações estão nas obras que compõem tanto a ideia de cânone como de autor, isto é, na leitura das edições modernas ou nas

\footnotetext{
${ }^{19}$ Tradução: Quanto mais importante a peça ou o autor proposto, maior é o nível de ceticismo que um caso de autoria irá levantar.

${ }^{20}$ Todas estas peças possuem edições modernas e acessíveis, Philaster pela Arden Early Modern Drama (2009); The Tamer Tamed pela Revels Student Editions (2007); The Sea Voyage na Revels Plays, pelo título de Three Renaisssance Travel Plays (2000).
} 
CLOSEL - Shakespeare e a prática da colaboração...

traduções disponíveis, por exemplo, de Macbeth, Measure for Measure ou Timon of Athens, estamos em contato com a mão de Thomas Middleton além de Shakespeare.

Os textos do terceiro grupo de peças colaborativas são aqueles em que Shakespeare realizou algum incremento ou modificação, para o qual geralmente usa-se o termo "adição" para se referir a essa prática, como Sir Thomas More (1603-4, adições) — que será detalhada mais abaixo - e King Edward III (1596). Estas já foram consideradas peças fora do cânone ou "apócrifas". No entanto, vêm ganhando espaço no chamado cânone shakespeariano. King Edward III, há um tempo considerável, possui lugar nas obras completas da New Cambridge Shakespeare e Oxford Shakespeare e tem uma edição anunciada para os próximos anos na Arden Shakespeare, além de já contar com uma tradução para a língua portuguesa (Shakespeare, 2010b). Uma terceira peça disputa lugar neste grupo, pois estudos recentes - Stevenson (2008), Craig \& Kinney (2009) e Vickers (2012) - identificaram, por métodos distintos, que a adição feita à quarta versão da Spanish Tragedy (Q4-1602) de Thomas Kyd pode ter sido escrita por Shakespeare. Além destas, Arden of Faversham (1592-5) — uma peça colaborativa cuja autoria é desconhecida - , tem uma de suas cenas com grande possibilidade de ter sido escrita por Shakespeare (Craig \& Kinney, 2009, p. 78-99; Jowett, 2013, p. 88), totalizando treze obras, nas quais Shakespeare teria trabalhado em colaboração adicionando ou recebendo uma adição em sua obra. Afora Arden of Faversham e a Spanish Tragedy, as outras duas são geralmente analisadas a partir de estudos textuais, autoria, datação e atribuição.

No quarto grupo, podem-se englobar as demais peças que foram atribuídas a Shakespeare após a publicação do Primeiro Fólio, como aquelas publicadas junto com Pericles no Terceiro Fólio ${ }^{1}$ - em geral chamadas de apócrifas - e aquelas que pertenceram ao King's Men, como Arden of Faversham (1592-5), que ainda não foi publicada em uma coleção shakespeariana, e Mucedorus (Q1-1598; Q3-1610, adições), além de outras como Double Falsehood, no século XVIII. Esta última é um dos casos mais complexos, devido a sua história de transmissão e por se tratar da reelaboração de uma peça perdida, Cardenio, escrita em colaboração com Fletcher, que ganhou lugar na Arden Shakespeare Third Series, podendo ser lida, estudada, encenada e avaliada por um público maior. Outra situação complicada, e ainda em discussão, diz respeito a King Henry VI Part II (1591) e Part III (1591), na qual a sequência, datação e autoria das três 
CLOSEL - Shakespeare e a prática da colaboração...

partes compõem um problema para sua definição, ainda que raramente não sejam consideradas colaborativas (Taylor, 1997; Cox \& Rasmussen, 2001; Knowles, 2001). Ambas também poderiam ser encaixadas no grupo de peças alteradas, porém, parecem se situar melhor em peças com as definições de atribuições e colaborações em aberto.

Recentemente, em 19 de abril de 2012, Laurie Maguire e Emma Smith, em um artigo intitulado "Many Hands - A New Shakespeare Collaboration?", disponível na Internet, propuseram a possibilidade de All's Well that Ends Well (1604-5) ser uma peça colaborativa entre Shakespeare e Middleton, a partir de elos com Measure for Measure, como foi visto acima, na qual Middleton realizou adaptações. O artigo teve repercussão em diversos jornais britânicos. Poucos dias após a publicação, em 9 de maio de 2012, Vickers e Marcus Dahl, em “All's Well that Ends Well: an attribution refuted”, e um segundo artigo, mais técnico, por Dahl, “A New Shakespeare Collaboration? All's Not Well (in the data)", contestaram a referida atribuição, apontando falhas metodológicas — baseadas em práticas já não utilizadas — que impediriam algumas das conclusões. Ainda sobre a questão de colaboração entre Middleton e Shakespeare, Vickers e Dahl também condenam, através de justificativas semelhantes, as atribuições entre Shakespeare e Middleton, em especial em Macbeth, um caso em que as duas canções de The Witch $(1616)^{21}$ de Middleton reaparecem na peça do rei escocês (III.v e IV.i), tese defendida por diversos críticos desde 1869 (Bentley, 1971, p. 139-140; Taylor \& Jowett, 1993, p. 123-140; Taylor, 1997, p. 128-129; Jowett, 2013, p. 88). A tabela a seguir sintetiza a classificação das peças explicadas acima.

Tabela 1: Relação de peças colaborativas por grupo

\begin{tabular}{l|ll}
\hline \multirow{2}{*}{ Grupo } & Peças & Colaborador(es) \\
\hline \multirow{4}{*}{$\begin{array}{l}\text { GRUPO 1 } \\
\text { Peças escritas } \\
\text { colaborativamente }\end{array}$} & Titus Andronicus (1592) & George Peele \\
\cline { 2 - 3 } & Kimon of Athens $(1605)$ & Thomas Middleton \\
\cline { 2 - 3 } & King Henry VI Part I (1592) & $\begin{array}{l}\text { Thomas Nashe } \\
\text { Uma mão não identificada }\end{array}$ \\
\cline { 2 - 3 } & Pericles $(1607)$ & George Wilkins \\
\cline { 2 - 3 } & King Henry VIII (1613) & John Fletcher \\
\cline { 2 - 3 } & Cardenio $(1612-3)$ & John Fletcher \\
\cline { 2 - 3 } & Macbeth $(1606)$ & John Fletcher \\
\hline \multirow{2}{*}{$\begin{array}{l}\text { GRUPO 2 } \\
\text { Peças alteradas }\end{array}$} & Macbeth $(1606)$ & Thomas Middleton \\
\cline { 2 - 3 } & Measure for Measure (1603) & Thomas Middleton \\
\hline
\end{tabular}

\footnotetext{
${ }^{21}$ Para esta data foi utilizada a The Collected Works de Thomas Middleton, (Taylor \& Lavagnino, 2007).
} 
CLOSEL - Shakespeare e a prática da colaboração...

\begin{tabular}{|c|c|c|c|}
\hline Grupo & Peças & \multicolumn{2}{|c|}{ Colaborador(es) } \\
\hline \multirow{4}{*}{$\begin{array}{l}\text { GRUPO } 3 \\
\text { Peças com adições por } \\
\text { Shakespeare }\end{array}$} & Sir Thomas More (1603-4) & \multicolumn{2}{|c|}{$\begin{array}{l}\text { Anthony Munday } \\
\text { Thomas Dekker } \\
\text { Thomas Heywood } \\
\text { Henry Chettle } \\
\text { Mão C }\end{array}$} \\
\hline & The Spanish Tragedy $(\mathrm{Q} 4,1602)$ & $\begin{array}{l}\text { Thomas Kyd } \\
\text { Ben Jonson }\end{array}$ & \\
\hline & King Edward III (1596) & $\begin{array}{l}\text { Combinações } \\
\text { entre estes } \\
\text { dramaturgos }\end{array}$ & $\begin{array}{l}\text { Christopher Marlowe } \\
\text { George Peele } \\
\text { Thomas Kyd } \\
\text { Michael Drayton } \\
\text { Robert Greene }\end{array}$ \\
\hline & Arden of Faversham (1592-5) & \multicolumn{2}{|c|}{ Uma ou mais mãos não identificadas } \\
\hline \multirow{7}{*}{$\begin{array}{l}\text { GRUPO } 4 \\
\text { Peças com atribuições } \\
\text { em discussão }\end{array}$} & Arden of Faversham (1592-5) & \multicolumn{2}{|c|}{ Uma ou mais mãos não identificadas } \\
\hline & Double Falsehood (1727) & \multicolumn{2}{|c|}{$\begin{array}{l}\text { John Fletcher } \\
\text { Lewis Theobald }\end{array}$} \\
\hline & All's Well that Ends Well (1604-5) & \multicolumn{2}{|c|}{ Thomas Middleton } \\
\hline & Mucedorus $(\mathrm{Q} 3,1610)$ & \multicolumn{2}{|c|}{ Uma ou mais mãos não identificadas } \\
\hline & King Henry VI Part II (1591) & \multicolumn{2}{|c|}{$\begin{array}{l}\text { Christopher Marlowe } \\
\text { George Peele } \\
\text { Robert Greene } \\
\text { Thomas Nashe } \\
\text { Thomas Kyd }\end{array}$} \\
\hline & King Henry VI Part III (1591) & \multicolumn{2}{|c|}{$\begin{array}{l}\text { Christopher Marlowe } \\
\text { George Peele } \\
\text { Robert Greene }\end{array}$} \\
\hline & Apócrifas & \multicolumn{2}{|c|}{ Diversos e anônimos } \\
\hline
\end{tabular}

Fontes: Bentley (1971); Taylor \& Jowett (1993); Taylor (1997); Wells \& Taylor (1997); Burns (2000); McMullan (2000); Cox \& Rasmussen (2001); Knowles (2001); Proudfoot (2001); Rasmussen (2001); Bate (2002); Potter (2002) Vickers (2004; 2012); Wells (2006); Dawson (2008); Craig \& Kinney (2009); Hammond (2010); Jowett (2011; 2012; 2013); McManus \& Munro (2011); Dahl (2012); Maguire \& Smith (2012); Melchiori (2012); Vickers \& Dahl (2012).

Entretanto, afora os debates sobre metodologias de atribuição citados acima, um resultado diferenciado tem se apresentado no campo teatral. Em março de 2013, a companhia Hoosier Bard - fundada pelo diretor Terri Bourus e Gary Taylor — e a Oxford Shakespeare colocaram em cartaz duas versões de Measure for Measure, aquela que geralmente é encontrada — com as adições de Middleton — nas edições modernas e a outra mais antiga, cuja ambientação é mudada de Viena para Ferrara. A produção recebeu o título de "A Tale of Two Cities" e no folder pode-se ler claramente "escrita por William Shakespeare e adaptada por Thomas Middleton". 22 Assim, ambos os textos

\footnotetext{
${ }^{22}$ A peça, em sua versão ambientada em Ferrara foi encenada durante três dias; na outra semana, durante três dias também, passava a ser a versão em Viena. Este mesmo grupo também preparou uma versão de Cardenio. Mais informações sobre a produção podem ser encontradas em: <http://indyfringe.org/measure-measure> e <http://liberalarts.iupui.edu/shakespeare/productions/>. Acesso em 30 abr 2013.
} 
CLOSEL - Shakespeare e a prática da colaboração...

puderam passar das discussões acadêmicas sobre autoria e atribuição para o palco, encontrando, assim, atores, diretores e espectadores em uma união eficiente entre o universo teatral e o acadêmico. Também realizando essa transição, mas em sentido oposto — do teatro para o livro —, está a tradução de As You Like It (1599-1600) pela Cia. Elevador de Teatro Panorâmico, traduzido como "Do jeito que você gosta" (Shakespeare, 2012a). Nesta tradução, o diretor, Marcelo Lazzarato, e os atores envolvidos com a peça realizaram a tradução da peça de maneira colaborativa, cuja edição impressa resultante leva o nome do grupo como tradutor.

As duas consequências mais claras desse processo complexo tanto atual como moderno de estabelecimento e julgamento dos textos produziu, ao longo do tempo, seus efeitos colaterais: a depreciação dos textos em Quarto como sendo cópias piratas ou mal feitas $^{23}$ - quando comparadas aos textos que encontraram seu caminho para o Fólio e uma lista, de tamanho variado ${ }^{24}$, de peças consideradas apócrifas ou fora do cânone, das quais três vem ganhando espaço no cânone, Double Falsehood, King Edward III e Sir Thomas More. Dentre estas, segundo Richard Proudfoot, King Edward III e Sir Thomas More são peças com "aceitação canônica" (2001, p. 81).

Tratando, então, da peça Sir Thomas More, pode-se dizer que ela sintetiza essa discussão, ou mesmo que ela traz em suas folhas toda a complexidade de seu tempo e exemplifica, de maneira muito clara, a prática da colaboração, da censura ${ }^{25}$ e da revisão. A peça dedicada ao ilustre Lorde Chanceler de Henrique VIII é o resultado das diversas dinâmicas culturais daquele período, como o envolvimento de muitas pessoas na elaboração de uma peça, a relação com o censor e até mesmo a designação de atores enquanto a peça era concebida ou transcrita. Sir Thomas More se encontra preservada como um manuscrito, sob o número MS 7368, no British Museum, em Londres. Conhecido também como "The Booke of Sir Thomas More", o documento carrega consigo essas marcas do labor teatral de seu tempo. Suas vinte folhas legaram muito trabalho de identificação de seus autores e de sua datação à posteridade crítica. Cerca de seis autores diferentes foram identificados na composição de Sir Thomas More. O manuscrito, inicialmente escrito por Anthony Munday e Henry Chettle, passou por um

\footnotetext{
${ }^{23}$ John Jowett aborda a importância destas peças em Shakespeare and Text (2012, p. 93-98).

${ }^{24}$ Tucker Brooke, em 1908, reuniu catorze peças que naquele período eram consideradas apócrifas. A edição é uma porta de entrada para essas peças relegadas às notas de rodapé. Ver Brooke (1929).

${ }_{25}$ Tratei de forma diferenciada o assunto da censura em um evento dedicado ao tema do Drama e Censura, realizado na Faculdade de Letras da Universidade do Porto em 2012. Ver Closel (2013).
} 
processo pesado e complexo de revisão e censura, recebeu contribuições substanciais adições e revisões - de William Shakespeare, Thomas Dekker e Thomas Heywood, e por fim, um copista, identificado como Mão C teria organizado o texto (Cf. Jowett, 2011). Infelizmente, não há registro de encenação da peça até meados do século XX. Geralmente $^{26}$ se classificam as datas desta peça, em duas partes, o texto original, possivelmente composto no início da última década do século XVI (1592-3), e as adições nos primeiros anos de James I, entre 1603-4.

Antes de adentrar as características sobre a colaboração e seus reflexos para a tradução ${ }^{27}$ para a língua portuguesa, é justo salientar a importância de Sir Thomas More não somente como um documento teatral, mas como uma peça elisabetana digna tanto de atenção crítica como de análise literária e textual. Assim como a prática da colaboração requer o afastamento de conceitos modernos como cânone e autoria, a discussão sobre a sua relevância também exige atenção ao momento histórico em que foi escrita e ao qual se remete além das diversas obras que a cercam e com as quais dialoga.

A peça sobre o autor da Utopia, se examinada como uma estrutura, pode ser colocada dentro de uma tradição de estudo moral-biográfico-político, em grande expansão no período elisabetano desde o Mirror for Magistrates (1559) - obra que dialoga com diversas peças de teatro - , que uma vez transposta para o gênero dramático ganhou tons de tragédia, ao mesmo tempo em que, neste caso, também é uma peça histórica. Por tratar de toda ascensão e queda da vida de um homem notável, deixa algum espaço para reflexão sobre o "erro" cometido pela personagem que culmina em sua própria morte. More passa a ser uma personagem histórica, trágica e por isso mesmo exemplarmente adequada a uma tradição que tende a enquadrar a tragédia sob a óptica moralizante dos casos trágicos da vida de homens ilustres, cujas quedas ensejavam reflexão política e social, iluminando um caminho fatídico a ser evitado. Traços claros da fascinante figura histórica do Chanceler da Inglaterra são preservados

\footnotetext{
${ }^{26}$ Outras possibilidades já foram apresentadas, como a elaboração de um dos editores da peça Giorgio Melchiori (2009 [1989]). No entanto, evidências externas e internas — como a morte de Elizabeth I e o novo censor, além de relações com peças escritas em 1603-4 — apontam para a datação posterior, como é o caso defendido por Gary Taylor (2009 [1989], p. 120-125), John Jowett (2011), entre outros. A visão que coloca as adições em um momento posterior é aquela seguida neste texto e no projeto ao qual se relaciona.

${ }^{27}$ Realizo a primeira tradução para o português e um estudo crítico de Sir Thomas More em meu Doutorado no IEL-UNICAMP com apoio da FAPESP, sob orientação da Profa. Dra Suzi Frankl Sperber.
} 
pelos próprios formatos que a peça toma em suas relações com as mais importantes tendências políticas e artísticas de sua época. Por outro lado, a peça tem uma profundidade de reflexão e representação do martírio que ecoa uma vida de santo.

A polêmica da existência ou não da "mão de Shakespeare" nesta peça não é o argumento para que ela seja estudada e traduzida, e sim o seu valor dramático, histórico e estético, pois se trata de uma peça fundamental para a compreensão das origens históricas do período elisabetano. Pelo viés teatral, há o processo de escrita, revisão e censura ao qual o fenômeno teatral estava sujeito; historicamente, por se tratar de uma das poucas peças que - por ter sobrevivido à censura - aludem a temas fundamentais como o divórcio de Henrique VIII, a Reforma Protestante e o rompimento com a Igreja Católica, além de assuntos difíceis como revoltas populares e xenofobia; e, esteticamente, por conservar de forma bem caracterizada, em uma de suas cenas, as práticas teatrais inglesas dos interlúdios e moralidades do início do século XVI.

Com uma ideia mais clara do local em que este drama se encaixa dentro do universo elisabetano-jacobino, pode-se avançar na discussão da composição física da peça de Sir Thomas More e sua tradução para a língua portuguesa. Das vinte folhas que compõem o manuscrito, cerca de treze correspondem ao texto original, e o restante às adições feitas posteriormente. Cada um dos participantes - enquanto suas identificações ainda não haviam se estabelecido — foram chamados de "mão" acompanhada de uma letra. Shakespeare, por exemplo, foi identificado como a Mão D. Segundo Jowett, as folhas que compõem as adições são todas escritas em papéis que não correspondem um com o outro, sendo, portanto, provenientes de fontes diferentes (2011, p. 362-367).

As adições totalizam seis intervenções no texto, divididas em cinco pessoas; cada intervenção corresponde a um novo momento em que folhas são adicionadas ao texto original. Algumas delas substituem textos que fazem parte da versão com adições, mas já não integram a peça como vem sendo modernamente editada. Em outros casos, as adições complementam cenas e criam outras sem que necessariamente uma parte do texto seja substituída. Essa característica oferece ao leitor possibilidades distintas de leitura, expandindo a compreensão do texto a partir de variações para as cenas. $\mathrm{Na}$ tabela abaixo, é possível observar como cada um dos dramaturgos estava envolvido com a peça. 
CLOSEL - Shakespeare e a prática da colaboração...

Tabela 2: Colaboradores envolvidos em Sir Thomas More

\begin{tabular}{|c|c|c|}
\hline Código & Identificação & Intervenção \\
\hline Mão A & Henry Chettle & Adição I: partes da cena xiii \\
\hline Mão B & Thomas Heywood & $\begin{array}{c}\text { Adição II: cena iv } \\
\text { Adição VI: final da cena ix }\end{array}$ \\
\hline Mão C & Escriba desconhecido & $\begin{array}{c}\text { Adição II: transcreveu a cena v } \\
\text { Adição III: transcreveu o início da cena viii } \\
\text { Adição IV: transcreveu a cena viii } \\
\text { Adição V: transcreveu o início da cena ix }\end{array}$ \\
\hline Mão D & William Shakespeare & $\begin{array}{l}\text { Adição II: grande parte da cena vi } \\
\text { Adição III: início da cena viii (possibilidade) } \\
\text { Adição V: início da cena ix (possibilidade) }\end{array}$ \\
\hline Mão E & Thomas Dekker & Adição IV: final da cena viii \\
\hline
\end{tabular}

Fonte: Jowett (2011, p. 6; 348-350; 383-393; 2013, p. 92-94)

A peça completa possui dezessete cenas, das quais, pela tabela acima, é possível ver que seis possuem intervenções de outros dramaturgos. Em volume de folhas, isso significa sete das vinte páginas que compõem o manuscrito.

Além dos dramaturgos, a mão identificada como Mão C foi responsável por tornar todo o conjunto orgânico, trabalhando como um escriba teatral, unindo o texto original às adições e fazendo substituições e cortes. Isso se deve, possivelmente, ao fato do texto original, escrito previamente, ter sido censurado. As adições, embora não sigam as instruções do censor, Edmund Tilney, procuram adequá-la aos critérios de aprovação da época (Cf. Jowett, 2011; Taylor, 2009 [1989]). A censura tem um impacto valioso para a peça, pois esse tipo de marcação somente se conserva nos manuscritos. Segundo Bentley, quando estes não encontravam problemas, as peças recebiam a autorização para a encenação (1971, p. 145-167). A sobrevivência do manuscrito com as marcas de Tilney e o devido destaque desse tipo de item permite que o leitor verifique aquilo que não agradou o censor e imagine que tipo de repercussão elas teriam. Ainda que a peça tenha recebido um aviso cuidadoso em sua primeira folha, vale lembrar que o papel do censor, conforme aponta Jowett, era de tornar a peça encenável (2011, p. 26-27).

Pelos critérios de Bentley, em The Profession of Dramatist in Shakespeare's Time (1971, p. 167), é fácil constatar que Sir Thomas More toca em praticamente todos os pontos críticos que levariam uma peça a ser recusada quando coloca em cena um mártir cristão, manifestações de xenofobia e uma insurreição. Porém, a questão 
diplomática fora a que mais chamou a atenção do censor. Em sua anotação Tilney deixa um recado, na margem da primeira folha:

Leave out the insurrection wholly and the cause thereof, and begin with Sir Thomas More at the Mayor's sessions, with a report afterwards of his good service done being Sheriff of London upon a mutiny against the Lombards — only by a short report, and not otherwise, at your own perils.

E. Tilney

(Sir Thomas More, início da peça $)^{28}$

Nenhum dos colaboradores que trabalharam nas adições posteriores procurou seguir totalmente essa orientação, e a peça seguiu com a insurreição. $O$ termo Lombardo, por exemplo, é uma das formas que Tilney encontrou para suavizar as referências aos estrangeiros. Tilney risca palavras como "franceses" e escreve "lombardos" no lugar. De maneira semelhante ele risca "ingleses" e substitui por palavras diplomaticamente mais neutras, como "homem". Portanto, busca, desta forma, desreferenciar a peça de qualquer situação diplomática delicada.

No que toca às colaborações de Shakespeare ${ }^{29}$, referentes às cenas vi, viii e ix da peça, são momentos que envolvem solilóquios, dos quais os dois primeiros serão tratados brevemente. No principal deles, na cena vi, More se dirige a uma turba de ingleses que se levantaram contra os imigrantes devido aos diversos crimes e atrocidades aos quais esses londrinos de áreas mais afastadas da cidade vinham sendo submetidos. A parte shakespeariana da cena corresponde a 147 linhas, envolvendo os diálogos iniciais, a chegada de More, seu discurso e a rendição dos revoltosos às autoridades. O discurso ecoa, como foi notado por muitos críticos, o famoso e muito citado discurso de Ulisses em Troilus and Cressida (1602). Nele, More pede que os revoltosos se coloquem no lugar daqueles que eles pretendem destruir, neste caso, os estrangeiros, incentivando a tolerância àquele que é diferente, isto é, de quem não é inglês. Apesar da beleza da passagem, muitos observaram que ela é bem diferente do restante da peça, em diversos aspectos (Taylor, 2009 [1989], p. 122; Melchiori, 2009

\footnotetext{
${ }^{28} \mathrm{O}$ texto estabelecido como base para as passagens citadas ao longo deste texto é da edição preparada por John Jowett (2011) pela Arden Shakespeare Third Series.

${ }^{29}$ Diversos críticos, ao longo do tempo, testaram e afirmaram a autoria de Shakespeare para as 147 linhas de Adição II, na cena VI, entre eles, E. M. Thompson (1923), W. W. Greg (1923), C. J. Sisson (1954), Harold Jenkins (1961), Peter W. M. Blayney (1972), G. Blakemore Evans (1974), Charles Hamilton (1985), P. J. Croft (1987), R. E. Alton (1987), Taylor (1987) e Giles Dawson (1990) (Taylor, 1997, p. 124; Taylor, 2009 [1989], p. 101-2; Jowett, 2011, p. 440).
} 
CLOSEL - Shakespeare e a prática da colaboração...

[1989], p. 94-95). Em uma das partes mais significativas desta longa adição, quando os revoltosos dizem que não estão se levantando contra Deus, More diz:

\section{MORE}

Nay, certainly you are.

For to the king God hath his office lent

Of dread, of justice, power and command;

Hath bid him rule, and willed you to obey.

And, to add ampler majesty to this,

He hath not only lent the king His figure,

His throne and sword, but given him His own name,

Calls him a god on earth. What do you, then,

Rising 'gainst him that God Himself installs,

But rise 'gainst God? What do you to your souls

In doing this? O, desperate as you are,

Wash your foul minds with tears, and those same hands

That you, like rebels, lift against the peace,

Lift up for peace; and your unreverent knees,

Make them your feet. To kneel to be forgiven

Is safer wars than ever you can make

Whose discipline is riot.

In, in, to your obedience! Why, even your hurly

Cannot proceed but by obedience.

Tell me but this: what rebel captain,

As mutinies are incident, by his name

Can still the rout? Who will obey a traitor?

Or how can well that proclamation sound

When there is no addition but 'a rebel'

To qualify a rebel? You'll put down strangers,

Kill them, cut their throats, possess their houses

And lead the majesty of law in lyam

To slip him like a hound. Alas, alas! Say now the King,

As he is clement if th' offender mourn,

Should so much come too short of your great trespass

As but to banish you: whither would you go?

What country, by the nature of your error,

Should give you harbour? Go you to France or Flanders,

To any German province, to Spain or Portugal,

Nay, anywhere that not adheres to England:

Why, you must needs be strangers. Would you be pleased

To find a nation of such barbarous temper

That, breaking out in hideous violence,

Would not afford you an abode on earth,

Whet their detested knives against your throats,

Spurn you like dogs, and like as if that God

Owed not nor made not you, nor that the elements

Were not all appropriate to your comforts

But chartered unto them? What would you think

To be thus used? This is the strangers' case,

And this your mountanish inhumanity.

(Sir Thomas More, cena vi, versos 111-156) 
Os versos sublinhados no solilóquio acima foram marcados pela Mão C para serem removidos, assim como também duas palavras riscadas mais abaixo. A passagem possui uma retórica que não tem muitos equivalentes na peça, como interrupções de pensamento e mudanças de tempos verbais. A tradução busca preservar e comentar esses efeitos, assim como manter os registros do censor e do escriba desconhecido que leu esses versos pela primeira vez e marcou aquilo que não achou adequado. Ao longo desta adição, Shakespeare não se preocupa com os nomes dos outros personagens que estão em cena - referindo-se a "Other", "Oth" ou "O" — ou com a marcação da entrada de Thomas More, mas deixa espaço no papel para isso. Esses itens foram ajustados pela Mão C, e, em alguns casos, pelos editores da peça. Segundo Jowett, isso expressa a simbiose do processo colaborativo entre dramaturgo e escriba teatral (2013, p. 94). Quando o perdão é oferecido, alguns versos depois, o texto retorna para o verso no texto de Anthony Munday.

\section{MORE}

Submit you to these noble gentlemen,

Entreat their mediation to the King,

Give up yourself to form, obey the magistrate,

And there's no doubt but mercy may be found

If you so seek it.

ALL CITIZENS

We yield, and desire his highness' mercy.

(Adição II)

SHAKESPEARE MUNDAY

(Original)

They lay by their weapons

(Sir Thomas More, cena vi, versos 161-165)

Neste caso, e ao longo de toda a tradução, além das marcações de censura ou eliminação de versos, anotações às margens têm feito o papel de manter os registros textuais, em especial demarcar as separações entre um colaborador e outro, ou mesmo manter outros registros do manuscrito, em casos como quando um deles escreveu o nome de um ator próximo de uma rubrica.

A segunda intervenção de Shakespeare, ainda que essa não seja tão aceita como a anterior, sobrevive como uma transcrição da Mão C, adição III, cena viii, que pode conter, por se tratar do texto na letra do escriba, alguns versos eliminados. Esta adição é curiosa, pois se trata de um pedaço de papel colado na parte inferior da folha 14A (frente da $14^{\mathrm{a}}$ folha), substituindo 61 versos de Munday por 21 versos atribuídos a 
Shakespeare. Os versos substituídos podem ser consultados, pois a adição foi descolada do manuscrito, sendo possível, desta forma, ler o texto original que fora descartado ${ }^{30}$. A cena segue imediatamente ao relato, na cena vii, em que o leitor/espectador fica sabendo, através de um mensageiro, que além do perdão aos revoltosos, o Rei concedeu o cargo de Lorde Chanceler da Inglaterra a Thomas More, o posto mais alto que este poderia alcançar. Ao iniciar a cena viii, More é, agora, Lorde Chanceler, e reflete sobre a nova posição, observando os instrumentos de autoridade, o Bastão e a Bolsa.
MORE
It is in heaven that I am thus and thus,
And that which we profanely term our fortunes
Is the provision of the power above,
Fitted and shaped just to that strength of nature Which we are born with. Good God, good God, That I from such an humble bench of birth Should step, as 'twere, up to my country's head, And give the law out there; I, in my father's life, To take prerogative and tithe of knees From elder kinsmen, and him bind, by my place, To give the smooth and dexter way to me That owe it him ${ }^{31}$ by nature: sure these things, Not physicked by respect, might turn our blood To much corruption. But, More, the more thou hast, Either of honor, office, wealth, and calling, Which might accite thee to embrace and hub ${ }^{32}$ them, The more do thou in serpents' natures think them, Fear their gay skins with thought of their sharp state, And let this be thy maxim: to be great Is, when the thread of hazard is once spun, A bottom, great wound up, greatly undone. (Sir Thomas More, cena viii, versos 1-21)

Segundo Jowett, em geral, o uso de "thus and thus", na linha inicial, é creditado como shakespeariano, por ele ser o único dramaturgo a utilizar esta combinação de palavras. Ainda nos versos iniciais, são encontrados paralelos com Othello (1603-4) Ato I, cena iii, versos 320 e 326 a 329 - e King Lear (1605-6) - Ato I, cena ii, versos 1 a 3 -, nas falas de Iago e de Edmundo. Ambos refletem, como More, nas condições de seu nascimento, referenciando-se ao pai e à posição ora ocupada (2011, p. 454-5).

\footnotetext{
${ }^{30}$ Esta mesma situação, de uma parte ser colada ao texto original de Munday, ocorre novamente, com a adição V na cena IX, que também vem sendo discutida como shakespeariana.

${ }^{31}$ Referência ao pai de More, John More.

${ }^{32}$ Dupla de verbos vistos em Timon of Athens, Ato 1, cena i, verso 44 (Cf. Jowett, 2011, p. 218, n16).
} 
CLOSEL - Shakespeare e a prática da colaboração...

A colagem da adição termina logo após a última linha citada, e uma rubrica, separa o texto das adições do texto original. Neste caso, o ajudante de More entra e a cena segue com as brincadeiras de More na recepção de Erasmo de Rotterdam e no desenvolvimento de um caso muito significativo para a peça, um homem que está entre abrir mão de uma promessa ou ser preso.

A primeira intervenção de Shakespeare parece um pouco mais inacabada com relação à posterior; isso se deve, possivelmente, ao fato de que, no segundo caso, o texto já está mais envolvido na trama principal através da Mão C. As duas formas ilustram etapas diferentes do processo de colaboração. Cada uma das diversas adições e seus respectivos colaboradores possuem maneiras distintas de intervir no texto, sejam elas na mão do próprio dramaturgo ou na transcrição da Mão C. No caso das demais peças que Shakespeare escreveu ao lado de um colaborador ou daquelas em que é autor de alguma parte, a forma de trabalho não deve diferir muito do que pode ser observado no manuscrito de Sir Thomas More.

As implicações de todas essas características na tradução têm relevância quando se pensa, especialmente, nas expectativas do uso de uma edição, para leitura ou para ganhar vida no palco. Se o fenômeno da combinação não é visível na maior parte das traduções, isto é, não são levados para o leitor os problemas que são de cuidado da crítica textual, esse mesmo procedimento deveria ser feito em uma peça que toma corpo após décadas de discussões e posições diferenciadas quanto às escolhas de edição? Deveria a tradução deixar todas as marcas de censura, alternação entre autores, versos riscados, todos esses traços inerentes à riqueza e complexidade do documento que traz em suas folhas não somente uma peça de teatro, mas também o labor teatral que redefine as ideias de autoria e cânone, em especial no caso de Shakespeare? Tentar estabelecer um texto "singular" para Sir Thomas More parece não ser a solução quando se pensa em uma tradução para ser lida. A instabilidade do texto elisabetano é algo a se conservar através da tradução.

A situação se altera quando esse mesmo texto destina-se aos palcos, momento em que todos os dramaturgos envolvidos podem ter suas partes mescladas ao todo e os seus nomes não marcam mais alternâncias entre o texto original e as adições; eles passam a ser os nomes em um cartaz e os responsáveis por uma composição ainda heterogênea aos olhos modernos acostumados com a ideia de autor, mas cujo resultado, 
CLOSEL - Shakespeare e a prática da colaboração...

obtido pela peça, é perfeitamente harmônico e homogêneo. A colaboração e a tradução nesta peça são itens que transformam o tradutor em um herdeiro da pena da Mão C, cujo trabalho visa um equilíbrio entre a tarefa de um editor e um diretor teatral, um mediador entre o texto, o leitor e o espectador.

Ao recorrer, ao longo deste texto, a publicações, discussões e encenações que, em sua maioria, são bem recentes, espera-se que a relevância e a atualidade do assunto da colaboração no cenário shakespeariano atual tenha se mostrado como uma necessidade para se compreender os "produtos literários" atuais dentro e fora de seu próprio tempo. A questão da colaboração não é apenas uma problemática crítica que envolve o estabelecimento do texto, a desintegração de trechos ou o restabelecimento dos nomes que desaparecem no tempo, e sim uma grande mudança na relação entre obra/cânone e autor, que interfere — de maneira positiva - na maneira de ler, encenar, traduzir ou ensinar Shakespeare.

\section{Referências}

BATE, Jonathan. Introduction. In: SHAKESPEARE, William. Titus Andronicus. Edited by Jonathan Bate. The Arden Shakespeare Third Series. London: Thomson, 2002 [1995]. p. 1-122.

BEAUMONT, Francis et FLETCHER, John. Philaster, or Love Lies A-Bleeding. Arden Early Modern Drama. London: Methuen, 2009.

BENTLEY, Gerald Eades. The Profession of Dramatist in Shakespeare's Time. Princeton: Princeton University Press, 1971.

BROOKE, C. F. Tucker. The Shakespeare Apocrypha. Being a collection of fourteen plays which have ascribed to Shakespeare. Oxford: Clarendon Press, 1929 [1908].

BURNS, Edward. Introduction. In: SHAKESPEARE, William. King Henry VI Part I. Edited by Edward Burns. The Arden Shakespeare Third Series. London: Methuen, 2000. p. 1-103.

CHAMBERS, E. K. The Disintegration of Shakespeare. The Annual Shakespeare Lecture. London: Oxford University Press, 1924, epígrafe na p. 10. 
William Shakespeare: A Study of facts and problems. 2 vols. Oxford: Clarendon University Press, 1930.

CLOSEL, Régis Augustus Bars. Drama and Censorship in 'The Booke of Sir Thomas More'. In: MARINHO, Cristina (Org). Teatro do Mundo: Drama e Censura. Porto: UP, 2013 [no prelo].

COX, John D.; RASMUSSEN, Eric. Introduction. In: SHAKESPEARE, William. King Henry VI Part III. Edited by John D. Cox and Eric Rasmussen. The Arden Shakespeare Third Series. London: Thomson, 2001. p. 1-176.

CRAIG, Hugh et KINNEY, Arthur F. (Eds.). Shakespeare, Computers, and the Mystery of Authorship. Cambridge: Cambridge University Press, 2009.

DAHL, Marcus. A New Shakespeare Collaboration? All's Not Well (in the data). Institute of English Studies. 2012. Disponível em: <http://www.ies.sas.ac.uk/about-us/news/all\%E2\%80\%99s-well-ends-wellattribution-refuted>. Acesso em 30 abr. 2013.

DAWSON, Anthony B.; MINTON, Gretchen E. Introduction. In: SHAKESPEARE, William. Timon of Athens. Edited by Anthony B. Dawson and Gretchen E. Minton. The Arden Shakespeare Third Series. London: Cengage Learning, 2008. p. $1-152$.

DOBSON, Michael; WELLS, Stanley. The Oxford Companion to Shakespeare. Oxford: Oxford University Press, 2001.

EDMONDSON, Paul; WELlS, Stanley. Shakespeare Beyond Doubt. Evidence, Argument, Controversy. Cambridge: Cambridge University Press, 2013.

GOSSETT, Suzanne. Introduction. In: BEAUMONT, Francis et FLETCHER, John. Philaster, or Love Lies A-Bleeding. Arden Early Modern Drama. London: Methuen, 2009. p. 1-102. Introduction. In: SHAKESPEARE, William. Pericles, Prince of Tyre. The Arden Shakespeare Third Series. Edited by Suzanne Gossett. London: Thomson, 2004. p. 1-163. 
HAMMOND, Brean. Introduction. In: SHAKESPEARE, William. Double Falsehood or The Distressed Lovers. Edited by Brean Hammond. The Arden Shakespeare Third Series. London: Methuen, 2010. p .1-160.

HOWARD-HILL, T. H. (Ed.). Shakespeare and Sir Thomas More: Essays on the play and its Shakespearian Interest. New Cambridge Shakespeare Studies and Supplementary Texts. Cambridge: Cambridge University Press, 2009 [1989].

JOWETT, John. Introduction. In: MUNDAY, Anthony; SHAKESPEARE, William et al. Sir Thomas More. Edited by John Jowett. The Arden Shakespeare Third Series. London: Methuen Drama, 2011. p. 1-129.

Shakespeare and Text. Oxford Shakespeare Topics. Oxford: Oxford University Press, 2012 [2007].

. Shakespeare as Collaborator. In: EDMONDSON, Paul; WELLS, Stanley. Shakespeare Beyond Doubt. Evidence, Argument, Controversy. Cambridge: Cambridge University Press, 2013. p. 88-99.

KNOWLES, Ronald. Introduction. In: SHAKESPEARE, William. King Henry VI Part II. Edited by Ronald Knowles. The Arden Shakespeare Third Series. London: Thomson, 2001. p. 1-141.

MAGUIRE, Laurie; SMITH, Emma. Many Hands - A New Shakespeare Collaboration?. Blog for Centre for Early Modern Studies. University of Oxford. 19 abr 2012. Disponível em: <http://www.cems-oxford.org/projects/theauthorship-of-alls-well>. Acesso em: 29 abr. 2013.

MARTINS, Marcia A. P. Escolha o seu Shakespeare. Base de dados sobre traduções da obra de William Shakespeare para a língua portuguesa. 2012. Disponível em: <http://www.dbd.puc-rio.br/shakespeare/default.php>. Acesso em: 20 abr. 2013.

MCMANUS, Clare; MUNRO, Lucy. Introduction: Shakespeare and Fletcher, Fletcher and Shakespeare. Shakespeare, vol. 7, n. 3, p. 253-256, 2011.

MCMULLAN, Gordon Introduction. In: SHAKESPEARE, William; FLETCHER, John. King Henry VIII. Edited by Gordon McMullan. The Arden Shakespeare Third Series. London: Methuen Drama, 2000. p. 1-199. 
MELCHIORI, Giorgio. The Book of Sir Thomas More: Dramatic Unity. In: HOWARD-HILL, T. H. Shakespeare and Sir Thomas More: Essays on the Play and its Shakespearian Interest. New Cambridge Shakespeare Studies and Supplementary Texts. Cambridge: Cambridge University Press, 2009 [1989]. p. 77-100. Introduction. In: SHAKESPEARE, William. King Edward III. Edited by Giorgio Melchiori. The New Cambridge Shakespeare. Cambridge: Cambridge University Press, 2012 [1990]. p. 1-51.

MUNDAY, Anthony; SHAKESPEARE, William et al. Sir Thomas More. A play edited by The Rev. Alexander Dyce. London: Shakespeare Society, 1844.

. Sir Thomas More. Edited by John Jowett. The Arden Shakespeare Third Series. London: Methuen Drama, 2011.

. Sir Thomas More. Edited by The Royal Shakespeare Company. London: NHB, 2005.

. Sir Thomas More. Edited by V. Gabrielli and G. Melchiori. The Revels Plays. New York: Manchester UP, 2007.

. The Booke of Sir Thomas More. Edited by W. W. Greg, Oxford: Malone Society, 1911.

O'SHEA, José Roberto. Dessacralizando o "Verbo" Shakespeariano: Tradução Linguística e Cultural. In: SHAKESPEARE, William. Conto de Inverno. Tradução, notas e bibliografia de José Roberto O'Shea. Introdução de Marlene Soares dos Santos. São Paulo: Iluminuras, 2007. p. 29-36. . Introdução. In: SHAKESPEARE, William. O primeiro Hamlet In-Quarto de 1603. Oganização e tradução de José Roberto O'Shea. São Paulo: Hedra, 2010. p. 9-38.

William Shakespeare, George Wilkins e Péricles. In: SHAKESPEARE, William. Péricles, Príncipe de Tiro. Tradução, notas e bibliografia de José Roberto O’Shea. Introdução de Marlene Soares dos Santos. São Paulo: Iluminuras, 2012. p. 33-37. 
CLOSEL - Shakespeare e a prática da colaboração...

POTTER, Lois. Introduction. In: SHAKESPEARE, William; FLETCHER, John. Two Noble Kinsmen. Edited by Lois Potter. The Arden Shakespeare Third Series. London: Thomson, 2002. p. 1-130.

PROUDFOOT, Richard. Shakespeare: Text, Stage and Canon. Arden Shakespeare. London: Thomson: 2001.

RASMUSSEN, Eric. Collaboration. In: DOBSON, Michael; WELLS, Stanley. The Oxford Companion to Shakespeare. Oxford: Oxford University Press, 2001. p. $80-82$.

SHAKESPEARE, William; FLETCHER, John. King Henry VIII. Edited by G. McMullan. The Arden Shakespeare Third Series. London: Methuen Drama, 2000. Two Noble Kinsmen. Edited by Lois Potter. The Arden Shakespeare Third Series. London: Thomson, 2002.

Two Noble Kinsmen. Edited by Robert Kean turner and Patricia Tatspaugh. New Cambridge Shakespeare. Cambridge: Cambridge University Press, 2012.

SHAKESPEARE, William; MIDDLETON, Thomas. Timon of Athens. Edited by John Jowett. Oxford World's Classics. Oxford: Oxford University Press, 2004.

. Timon of Athens. Edited by Anthony B. Dawson and Gretchen E. Minton. The Arden Shakespeare Third Series. London: Cengage Learning, 2008.

SHAKESPEARE, William; WILKINS, George. Pericles, Prince of Tyre. The Arden Shakespeare Third Series. Edited by Suzanne Gossett. London: Thomson, 2004.

SHAKESPEARE, William. Conto de Inverno. Tradução, notas e bibliografia de José Roberto O'Shea. Introdução de Marlene Soares dos Santos. São Paulo: Iluminuras, 2007.

. Do jeito que você gosta, de William Shakespeare. Tradução Cia. Elevador de Teatro Panorâmico. São Paulo: Balão Editorial, 2012a.

Double Falsehood or The Distressed Lovers. Edited by Brean Hammond. The Arden Shakespeare Third Series. London: Methuen, 2010a.

Eduardo III. Tradução interlinear, introdução e notas por Elvio Funck. Porto Alegre: Movimento; Edunisc, 2010b. 
CLOSEL - Shakespeare e a prática da colaboração...

King Edward III. Edited by Giorgio Melchiori. The New Cambridge Shakespeare. Cambridge: Cambridge University Press, 2012b [1990].

. King Henry VI Part I. Edited by Edward Burns. The Arden Shakespeare Third Series. London: Methuen, 2000.

. King Henry VI Part II. Edited by Ronald Knowles. The Arden Shakespeare Third Series. London: Thomson, 2001.

. King Henry VI Part III. Edited by John D. Cox and Eric Rasmussen. The Arden Shakespeare Third Series. London: Thomson, 2001.

. King Richard III. Edited by James R. Siemon. The Arden Shakespeare Third Series. London: Methuen Drama, 2009.

O primeiro Hamlet In-Quarto de 1603. Oganização e tradução de José Roberto O’Shea. São Paulo: Hedra, 2010c.

Péricles, Príncipe de Tiro. Tradução, notas e bibliografia de José Roberto O’Shea. Introdução de Marlene Soares dos Santos. São Paulo: Iluminuras, 2012c.

. Titus Andronicus. Edited by Jonathan Bate. The Arden Shakespeare Third Series. London: Thomson, 2002 [1995].

SHAPPIRO, James. Contested Will: Who Wrote Shakespeare? London: Faber and Faber, 2010.

Quem escreveu Shakespeare? A história de mais de quatro séculos de disputa pela herança de uma autoria. Tradução de Liliana Negrello e Christian Schwartz. Curitiba: Nossa Cultura, 2012.

SIEMON, James R. The texts of Richard III. In: SHAKESPEARE, William. King Richard III. Edited by James R. Siemon. The Arden Shakespeare Third Series. London: Methuen Drama, 2009. p. 417-460.

STEVEnSON, Warren. Shakespeare's Additions to Thomas Kyd's The Spanish Tragedy: A Fresh Look at the Evidence Regarding the 1602 Additions. Lewinston: Mellen, 2008. 
TAYLOR, Gary; JOWETT, John. Shakespeare Reshaped: 1606-1623. Oxford Shakespeare Studies. Oxford: Clarendon Press, 1993.

TAYLOR, Gary; LAVAGNINO, John. (Eds.). The Collected Works of Thomas Middleton. Oxford: Oxford University Press, 2007.

TAYLOR, Gary. The Canon and the Chronology of Shakespeare's plays. In: WELLS, Gary; TAYLOR, Gary; JOWETT, John; MONTGOMERY, William. William Shakespeare: A Textual Companion. Reprinted with corrections. Oxford: Oxford University Press, 1997 [1987]. p. 69-144.

. The date and auspices of the additions to Sir Thomas More. In: HOWARDHILL, T. H. Shakespeare and Sir Thomas More: Essays on the Play and its Shakespearian Interest. New Cambridge Shakespeare Studies and Supplementary Texts. Cambridge: Cambridge University Press, 2009 [1989]. p. 101-129.

VICKERS, Brian; DAHL, Marcus. All's Well that Ends Well: an attribution refuted (with annotations). Institute of English Studies. 2012. Disponível em: <http://www.ies.sas.ac.uk/about-us/news/all\%E2\%80\%99s-well-ends-wellattribution-refuted> Acesso em: 30 abr. 2013.

VICKERS, Brian. Identifying Shakespeare's Additions to The Spanish Tragedy (1602): A New(er) Approach. Shakespeare, vol. 8, n. 1, p. 13-43, 2012. . Shakespeare, Co-Author: A Historical Study of Five Collaborative Plays. Oxford: Oxford University Press, 2004.

WELLS, Stanley. Shakespeare \& Co. New York: Pantheon Books, 2006.

WELLS, Stanley; TAYLOR, Gary; JOWETT, John; MONTGOMERY, William. William Shakespeare: A Textual Companion. Reprinted with corrections. Oxford: Oxford University Press, 1997 [1987]. 